\title{
ICT REGULATION PROCESS IN A CIVIL LAW, PERIPHERAL, AND MULTILEVEL ADMINISTRATION COUNTRY: HABERMAS' DELIBERATIVE PARADIGM REVISITED
}

\author{
José Antonio Gouvêa Galhardo \\ School of Economics, Business and Accounting - University of São Paulo (USP), Brazil
}

\begin{abstract}
What are the difficulties in the regulation process of new technologies in Brazil? To answer this question, we will adopt Habermas' concepts in a multi-method critical research. The positivist civil law system, multilevel administration, structural bottlenecks, conjuncture, and cultural trait may contribute to a competitive hurdle to the country. Additionally to describing the process, the purpose is to identify the unwarranted constraints to the communicative process and investigate the role of Academia. We intend to contribute with a review of Habermas' concepts towards the recognition of normative legitimacy over Information and Communications Technology (ICT) through the participation of technocrats and different fields of the Academia in the law-making process.
\end{abstract}

\section{KEYWORDS}

ICT Regulation, ICT Law-Making, Ethics, Habermas, Legislative Committee, Academia

\section{INTRODUCTION}

The ICT increasing advances, incredible solutions and innovations are opposed by the risks, uncertainties, and potential harms, or 'side effects' of these new technologies. Thus, the questions researchers (e.g. Fenwick, Kaal, \& Vermeulen, 2017) and organizations (e.g. Jensen, 2019) have been struggling to answer are: what, when and how to regulate something we do not even know how it works, what are the outcomes and who will pay for them? This was concern in the Technology Assessment movement in the early 70's, when the U.S. Congress established the Office of Technology Assessment to assist lawmakers in technical issues. Such assistance no longer exists, since the office was shut down in the mid 90's (Gedye, 2019), making it difficult to reach the ideal of governmental regulation towards the 'shared value' concept of Porter \& Kramer (2011).

For a country with a civil law system, multilevel administration with a complex distribution of the regulatory power, the law-making process can become a competitive obstacle to enter the $4^{\text {th }}$ industrial revolution, which is the case in Brazil.

The question this research intends to answer is: what are the difficulties in the regulation process of new technologies in Brazil.

The purposes are: identify the actors; describe the rule-making process in all levels of administration; identify and investigate the effectiveness of the channels of communication with the Academia; identify and investigate possible reasons for the difficulties; investigate the recognition of a competitive hurdle to the country; and compare the awareness and participation of different Academia (Business \& Administration, Computer Science \& Engineering, Law and Social Science) in this process.

The study has a critical research philosophical position, as we intend to go beyond the understanding and explaining of the phenomenon and try to question the established social structures and norms (Coombs, 2017) in the ICT law-making scenario based on Habermas' Theory of Communicative Action concepts.

We advocate that, paradoxically, ICT, which could be the way to enable the deliberative paradigm proposed by Habermas (Klein \& Huynh, 2004) is actually an issue in which the legitimacy of the rules relies much more on technocrats' will than on citizens' participation, which should be compensated by the participation of different fields of the Academia in the law-making process. 


\section{FOUNDATION}

\subsection{ICT Regulation Process Systematic Literature Review}

The systematic literature review of the ICT regulation process was conducted based on Bandara et al. (2015) proposed tool-supported literature review. We used the State of the Art through Systematic Review (StArt) literature-specific tool for planning and general management of the review.

The goal was to understand the ICT regulation process in a broad context. We started with a scope search through article alerts from various databases and follow-up of newsletters (e.g. ACM Tech News), resulting in a preliminary shortlist of 73 references. Since the nature of the subject embraces multiple domains (Bandara et al., 2015, p. 161), we used several available databases: ACM Digital Library; AIS Electronic Library; EBSCOhost; IEEEXplore Digital Library; ProQuest; SAGE journals; Scielo; ScienceDirect; Scopus; and Web of Science. In order to address the risk of bias due to the few contributions in law journals, we extended the search to Oxford Press Journals, Taylor \& Francis Online, and Springer databases.

We defined the following keywords for the literature search: ICT; Information and Communication Technology; Artificial Intelligence; Ethics; Law; Legal; Legislation; Normative; Regulation; Regulatory. The search was in English, Portuguese and Spanish. The time frame was from 2009 to July 2019. The search aimed at 'primary' articles, those specifically focused on the target topic (Bandara et al., 2015, p. 164), from journals and conference proceedings. The review protocol, strings, search dates, and filters used in each database were recorded in the StArt project file. Finally, a total of 10,451 articles were identified. StArt automatically excluded 2,487 duplicate entries. To select the papers, we used the Score Value calculated by StArt for each article. The articles in the first quartile (Score Value $\leq 3$ ) were rejected $(2,221)$ while those above the third quartile (Score Value $>14$ ) were accepted $(1,852)$, being the first exclusion and inclusion criteria.

The second exclusion criterion was the reading of titles and abstracts of the accepted papers. We obtained a sample of 518 articles that was imported to NVivo12, which we used in the coding and analysis stage.

During the screening of the articles, we noticed a new possible bias source concerning the imbalance in the different legal systems. Most of the law journals' papers were from common law countries (UK and USA). We investigated the top ten ranked law journals to minimize the risk. Upon identification, we crosschecked the data and found that 26 articles, in the $4^{\text {th }}$ quartile, had already been included in the accepted list of papers, while other 45 articles, in the $2^{\text {nd }}$ and $3^{\text {rd }}$ quartiles, were added to our sample. We searched the journals with no contribution and with an editorial line that suits our interest, and 35 additional articles were included. Therefore, we obtained a sample of 671 articles.

We started the quality assessment from the word cloud analysis in NVivo from which we chose 'law', 'legal', 'regulering', 'ethics', and 'policy' as drivers to focus on the target topic of the research. We conducted a new search by grouping the search queries with stemmed words automatically generated by the word cloud function. The result was ordered by frequency of the terms in each file, and we took the $4^{\text {th }}$ quartile as our primary literature sample, comprising 164 articles, which concentrated $57 \%$ of the total count of the target terms. Subsequently, the quality filtering was through the assessment of the impact factor of sources together with forward search of the primary literature. We used the average citation frequency per year base on Google Scholar tool. We took the impact factor from Scimago Journal Rank (2018 SJR and H Index) and from Google Scholar (2018 Google h5 index). We selected papers with higher Average citation per year and over the median value at least in two indexes.

Therefore, we obtained a corpus of 63 qualified 'primary' papers, which were coded in the first cycle by mixing the Attribute and Descriptive Coding methods.

\subsection{Findings}

Most of the articles were conceptual (63\%), a few were empirical (25\%), and the remaining were literature review, reinforcing the opportunity of empirical studies (North-Samardzic, 2019). This production conceptual nature assumed the form of essays (50\%), frequently without an express theoretical perspective (47\%). Habermas was the only author used as theoretical reference more than once, repeating North-Samardzic (2019) finding.

It was possible to recognize the connection described by Winfield \& Jirotka (2018) between ethical principles, standards and regulation. However, there was a predominance of the ethics studies addressing the 
solutions up to the standardization. At best, such studies recognized the importance and need of - 'the why'regulations to prevent or rule a certain aspect - 'the what' -, but a few tried to investigate 'the how'.

Regulation is essentially reactive (Petit, 2017). The problem is that today the speed of this evolution and the difficulty in predicting the impacts worsen the inability of legacy legislation to address the regulatory vacuum (Vogelsang, 2017). By adding to this scenario the challenges to the conventional border of national legal systems (e.g. Pagallo, 2012); the messy overlap of national rules of different agencies and levels of administration (Ghanavati, Rifaut, Dubois, \& Amyot, 2014); the asymmetry of lobbying power over regulators (Relly \& Schwalbe, 2016) innovated by social media power in shaping voters' preferences and, consequently, politicians' (Benvenisti, 2018), we will have a more accurate picture of the research field involving the ICT regulatory process.

This conclusion raises a necessary question: how can we assess regulatory bodies' actions and linkage with public engagement, which we agree to be necessary to build public trust in new technologies (Winfield \& Jirotka, 2018)?

\subsection{Habermas' Critical Theory}

This study is based on Jünger Habermas' social Theory of Communicative Action and its derived theoretical construction of Discourse Ethics and Discourse Theory of Law and Politics. The option offers a complex set of concepts, principles and rational-based framework (Klein \& Huynh, 2004) that is suitable to analyze the law-making process in an idealized deliberative democracy. Habermas' theory is recognized and has been used in different studies in the Information Systems (IS) field (e.g. Stahl, Doherty, \& Shaw, 2012; Schlagwein, Cecez-Kecmanovic, \& Hanckel, 2019).

\section{METHOD}

This is a mixed-method qualitative research divided into two stages.

\subsection{Committee Members and Technical Staff Stage}

The first stage of the research will focus on the political-technocrat environment. The three levels of public administration and their respective legislative houses will be studied. Additionally, to the central government, the State of São Paulo and its capital will be the object of the research. We identified the specialized committees that concentrate the discussions and preliminary law proposals involving new technologies, as well as their members for each legislative house. With respect to the executive branch, the study will focus on the offices (Ministry and Secretariats), whose main duty concerns science and technology policies. A summary of the object of the study in this first stage is presented in Table 1 and Table 2.

Table 1. Specialized Committees on ICT in the Legislative Houses of Every Level of Administration

\begin{tabular}{|c|c|c|c|c|}
\hline Level & Legislative House & Committee & Members $^{(a)}$ & Alternates $^{(a)}$ \\
\hline \multirow[t]{3}{*}{ Central/ Federal } & $\begin{array}{l}\text { Chamber of Deputies } \\
\text { (CD) }\end{array}$ & $\begin{array}{l}\text { Science and Technology, Communication and } \\
\text { Informatics Commission (CCTCI/CD) }\end{array}$ & 29 & 42 \\
\hline & & $\begin{array}{l}\text { Special Commission for the Bill 2303/2015 of } \\
\text { virtual currencies (CEVC/CD) }\end{array}$ & 32 & 21 \\
\hline & Federal Senate (FS) & $\begin{array}{l}\text { Science, Technology, Innovation, Communicatior } \\
\text { and Informatics Commission (CCT/FS) }\end{array}$ & 17 & 15 \\
\hline Regional/State/ & São Paulo State & Science, Technology, Innovation and Information & 11 & 9 \\
\hline County & Assembly (ALESP) & Commission (CCTII/ALESP) & & \\
\hline Local/Municipal & $\begin{array}{l}\text { São Paulo City Council } \\
\text { (CCSP) }\end{array}$ & $\begin{array}{l}\text { Transit, Transport and Economic Activity } \\
\text { Commission (CTTAE/CCSP) }\end{array}$ & 7 & - \\
\hline
\end{tabular}

Note: (a) Quantities refer to the current number of appointed politicians as per a search on Sep $9^{\text {th }}, 2019$. 
Table 2. Executive Offices Responsible for ICT Policies

\begin{tabular}{ll}
\hline Level & Executive Branch \\
\hline Central/Federal & Ministry of Science, Technology, Innovations and Communications (MCTIC) \\
& Management Committee for the Internet in Brazil (CGI.br) \\
& National Telecommunications Agency (Anatel) \\
Regional/State/County & State Secretary of Economic Development (SDESP) \\
Local/Municipal & Municipal Secretariat of Innovation and Technology (SITSP) \\
& Municipal Secretariat for Mobility and Transport (SMTSP) \\
\hline
\end{tabular}

The first step in this stage is the archival analysis of the following sources: Reports; Meeting Agenda, Proposals and Voting Records; Meeting Video/Audio; Public Audiences and Seminars; List of Speakers and Multimedia Presentations; and e-Participation Platform Records. They are all public sources available on the web pages of each legislative house and executive office.

The purpose is to explore this material in order to identify issues discussed, points of dispute, academic guidance, presentations of invited technocrats, and speeches and voting of members of the commissions, mainly those who can be interviewed in the next stage. A 'theoretical sampling' approach will be used as a strategy to map some of the questions to be individually addressed to the selected members of the Commissions and technocrats of the Executive offices. Similarly, the interview sampling strategy is not intended to generalization, but to try to reach the saturation with a broad representation of actors in terms of voting position, political party wing representation, academic background, and gender. The interviews will follow the dramaturgical model proposed by Myers \& Newman (2007) and the analysis of both the archival material and interviews will be carried out with NVivo 12 software.

At the end of this stage, the analysis should reveal how Habermas's concepts are expressed in the law-making process of new technologies, whose results will feed the next stage of the research.

\subsection{Academy Stage}

In this stage, the findings of the political-technocrat stage will be used in a survey with the Academia. The same questionnaire will be applied to a network of scholars from the following areas: Social Science, Law, Business \& Administration, and Computer Science \& Engineering.

The purpose is to validate the findings from the previous stage and assess the difference in awareness and experience in the participation in the law-making process among the academic areas.

The result will be subsequently discussed in an interview session with a sample of researchers in order to validate the conclusions and contribute with new insights.

\section{CONCLUSION}

The problem of the research is current and relevant to both business environment and social life. What makes the Brazilian context of ICT law-making an interesting one is its past leadership and supposed successful ICT law-making experience (Freedom of Information Act and Civil Rights Framework for the Internet), its current conjuncture (right-wing wave, economic stagnation and high unemployment, competing legislative agendas (e.g. moral, economic, pension, corruption, environmental, violence)), its structural bottlenecks (e.g. lack of basic infrastructure, poor educational performance), and its cultural trait (mistrust of politics, and the 'Brazilian way of fixing things' culture).

One limitation faced in the systematic literature review of ICT regulation process was the lack of law journals, and the risk of bias concerning the different legal systems, which we partly overcame by adopting Bandara's et al. (2015) suggestions.

This difficulty may also have contributed to the production imbalance in favor of the study of ICT-related ethics in the chain ethics-standard-regulation (Winfield \& Jirotka, 2018), giving rise to the main gap observed: the study of regulation process to assure the public trust in new technologies.

The moment offers a number of opportunities to empirical studies worldwide, using the rich conceptual framework found in the literature. And this is particularly important to emerging countries that already face constraints on physical infrastructure and human resource capacity (Walden \& Christou, 2018). Their own 
regulations cannot be an additional barrier to the integration into the $4^{\text {th }}$ industrial revolution, except as mere consumers of technology.

The possibility of being discussed with the work of different authors makes Habermas' theoretical framework a natural background to study ICT regulation process. We intend to contribute with a review of Habermas' concepts towards the recognition of normative legitimacy over ICT through the participation of technocrats and different fields of the Academia in the law-making process. Thus, we hope to contribute to the necessary, but well balanced, and prompt ICT regulation, through a better understanding of its process.

\section{REFERENCES}

Bandara, W., Furtmueller, E., Gorbacheva, E., Miskon, S., \& Beekhuyzen, J. (2015). Achieving Rigor in Literature Reviews: Insights from Qualitative Data Analysis and Tool-Support. Communications of the Association for Information Systems, 37, 154-204. https://doi.org/10.17705/1CAIS.03708

Benvenisti, E. (2018). Upholding democracy amid the challenges of new technology: What role for the law of global governance? European Journal of International Law, 29(1), 9-82. https://doi.org/10.1093/ejil/chy013

Coombs, C. (2017). Coherence and transparency: Some advice for qualitative researchers. Producao, 27, 1-8. https://doi.org/10.1590/0103-6513.006817

Fenwick, M., Kaal, W. A., \& Vermeulen, E. (2017). Regulation Tomorrow: What Happens When Technology Is Faster than the Law? American University Business Law Review, 6(3). Retrieved from http://digitalcommons.wcl.american.edu/aublrhttp://digitalcommons.wcl.american.edu/aublr/vol6/iss3/1

Gedye, G. (2019). How Congress Got Dumb on Tech — and How It Can Get Smart. Washington Monthly, April/May/.

Ghanavati, S., Rifaut, A., Dubois, E., \& Amyot, D. (2014). Goal-oriented compliance with multiple regulations. 2014 IEEE 22nd International Requirements Engineering Conference, $R E 2014$ - Proceedings, (i), 73-82. https://doi.org/10.1109/RE.2014.6912249

Jensen, S. (2019). The future of law making. 11th OECD Conference on Measuring Regulatory Performance. Retrieved from https://www.regjeringen.no/en/aktuelt/the-future-of-law-making/id2654543/

Klein, H. K., \& Huynh, M. Q. (2004). The critical social theory of Jürgen Habermas and its implications for IS research. Social Theory and Philosophy for Information Systems, (January 2004), 157-237.

Myers, M. D., \& Newman, M. (2007). The qualitative interview in IS research: Examining the craft. Information and Organization, 17(1), 2-26. https://doi.org/10.1016/j.infoandorg.2006.11.001

North-Samardzic, A. (2019). Biometric Technology and Ethics: Beyond Security Applications. Journal of Business Ethics. https://doi.org/10.1007/s10551-019-04143-6

Pagallo, U. (2012). Cracking down on autonomy: Three challenges to design in IT Law. Ethics and Information Technology, 14(4), 319-328. https://doi.org/10.1007/s10676-012-9295-9

Petit, N. (2017). Law and Regulation of Artificial Intelligence and Robots - Conceptual Framework and Normative Implications. SSRN Electronic Journal, (March), 1-31. https://doi.org/10.2139/ssrn.2931339

Porter, M. E., \& Kramer, M. R. (2011). Creating shared value. Harvard Business Review, 89(1-2).

Relly, J. E., \& Schwalbe, C. B. (2016). How business lobby networks shaped the U.S. Freedom of Information Act: An examination of 60 years of congressional testimony. Government Information Quarterly, 33(3), 404-416. https://doi.org/10.1016/j.giq.2016.05.002

Schlagwein, D., Cecez-Kecmanovic, D., \& Hanckel, B. (2018). Ethical norms and issues in crowdsourcing practices: A Habermasian analysis. Information Systems Journal, 29(4), 811-837. https://doi.org/10.1111/isj.12227

Stahl, B. C., Doherty, N. F., \& Shaw, M. (2012). Information security policies in the UK healthcare sector: A critical evaluation. Information Systems Journal, 22(1), 77-94. https://doi.org/10.1111/j.1365-2575.2011.00378.x

Vogelsang, I. (2017). Regulatory inertia versus ICT dynamics: The case of product innovations. Telecommunications Policy, 41(10), 978-990. https://doi.org/10.1016/j.telpol.2017.09.006

Walden, I., \& Christou, T. A. (2018). Legal and Regulatory Implications of Disruptive Technologies in Emerging Market Economies. In SSRN Electronic Journal. https://doi.org/10.2139/ssrn.3230674

Winfield, A. F. T., \& Jirotka, M. (2018). Ethical governance is essential to building trust in robotics and artificial intelligence systems. Philosophical Transactions A, (376). https://doi.org/10.2759/413916 